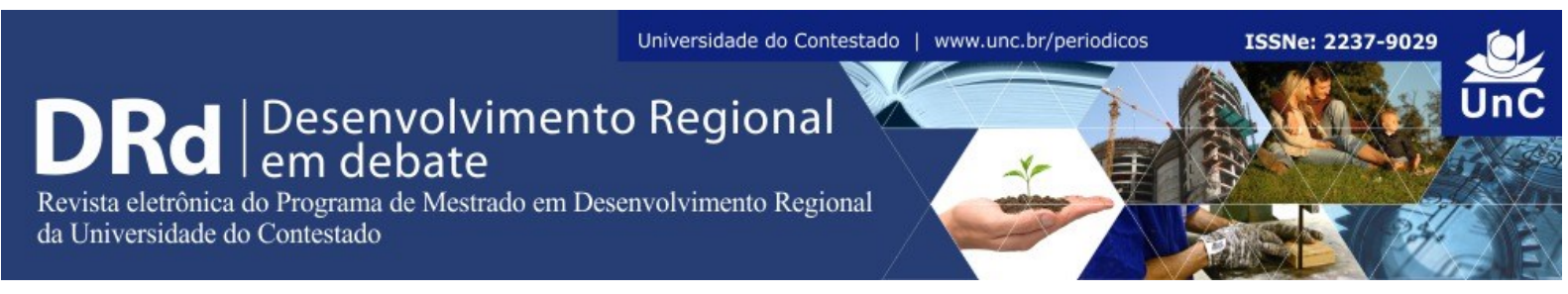

\title{
CAPITAL HUMANO E DESENVOLVIMENTO NO ESTADO DO PARANÁ ENTRE 2000 E 2010: UMA ANÁLISE ESPACIAL
}

\author{
Pietro André Telatin Paschoalino ${ }^{1}$ \\ Carlos Eduardo Caldarelli ${ }^{2}$ \\ Marcia Regina Gabardo da Camara ${ }^{3}$
}

\begin{abstract}
RESUMO
O objetivo deste estudo é estabelecer a relação entre desenvolvimento econômico e capital humano no estado do Paraná no período de 2000 e 2010. Desta monta, busca-se, por meio da Análise Exploratória de Dados Espaciais (AEDE), analisar a existência de associação espacial nos dados sobre o desenvolvimento nos municípios paranaenses. Utiliza-se, além da análise univariada das variáveis PIB per capita, Índice de Gini e Índice de desenvolvimento humano municipal - componente educação -, uma análise bivariada, podendo assim medir a autocorrelação espacial entre as variáveis e o capital humano (IDHM-Educação). Das variáveis descritivas conclui-se que houve melhora no desenvolvimento dos municípios do estado, porém, da AEDE infere-se que existe grande heterogeneidade nos dados de desenvolvimento dos municípios paranaenses, além de grandes faixas de clusters (aglomerações). É possível concluir que a variável capital humano esta altamente correlacionada tanto com a desigualdade de renda per capita, quanto com o PIB per capita nos municípios paranaenses.
\end{abstract}

Palavras-chave: Desenvolvimento Regional. Análise Espacial. Paraná.

\section{HUMAN CAPITAL AND DEVELOPMENT IN PARANÁ STATE BETWEEN 2000 AND 2010: A SPATIAL ANALYSIS}

\begin{abstract}
The objective of this Study is to stablish the relationship of economic development and human capital in the Paraná state in 2000 and 2010 period. In this way, seeks by Exploratory Spatial Data Analysis (ESDA) examine if exists spatial association in the data of development in municipalities of Paraná. It is used beyond the univariate analysis of the variables GDP per capita, Gini Index and municipal human development index - education component-, a bivariate analysis, thus being able to measure the spatial correlation between variables and human capital (IMHD-Education). Of descriptive variables we can conclude there was

\footnotetext{
${ }^{1}$ Economista, formado pela Universidade Estadual de Londrina. Atualmente sou mestrando do Programa de PósGraduação em Ciências Econômicas da Universidade Estadual de Maringá. Paraná, Brasil. E-mail: pietro telato@hotmail.com Departamento de Economia da Universidade Estadual de Londrina. Paraná. Brasil. E-mail: carlos.caldarelli@gmail.com Universidade Estadual de Londrina. Paraná. Brasil. E-mail: mgabardo@sercomtel.com.br
}

${ }^{2}$ Doutor em Economia Aplicada pela Escola Superior de Agricultura "Luiz de Queiroz". Professor do

${ }^{3}$ Doutora em Economia pela Universidade de São Paulo. Professora do Departamento de Economia da
\end{abstract}

DRd - Desenvolvimento Regional em debate (ISSNe 2237-9029)

v. 6, n. 3, p. 193-215, nov. 2016. 
improvement in the development of the municipalities, however, of ESDA is possible to infer that there is great heterogeneity in the data of development, in addition to large clusters (agglomerations). It is possible to conclude, the human capital variable this highly correlated to both the inequality of per capita income as with the GDP per capita in municipalities.

Keywords: Regional Development, Spatial Analysis, Paraná.

\section{INTRODUÇÃO}

Segundo Boisier (1989) o desenvolvimento de longo prazo de uma região, e não apenas o crescimento econômico, pode ser explicado pela interação de três forças. A primeira, refere-se à participação relativa no uso dos recursos da economia nacional. A segunda, seriam os efeitos (regionais) implícitos ou indiretos das políticas macroeconômicas e setoriais, podendo estas impulsionar ou prejudicar a trajetória de crescimento de determinada região. Em terceiro lugar, estão questões de cunho político, institucional e social. Cabe salientar que tais aspectos podem ser classificados como "capacidade de organização social da região". Assim, o desenvolvimento de uma região, diferente do crescimento, implica mudança na capacidade de internalizar o próprio crescimento.

Pode-se, portanto, compreender o desenvolvimento regional como dependente de aspectos econômicos, sociais, institucionais e políticos, medido muitas vezes por índices compostos, os chamados indicadores sintéticos, que levam em conta saúde, educação, renda, dentre outros. Desta feita, pode-se dizer que uma região aumentou seu nível de desenvolvimento quando a qualidade de vida e bem-estar da população melhorou (LIMA; CALDARELLI; CAMARA, 2014).

Segundo Lima e Simões (2010) a utilização do conceito de região é justificada pela hipótese de que a mesma cresce ou declina como um todo, ao invés de ter suas variações de renda como a soma aleatória de variações independentes nas atividades nela localizadas. Assim, pode ser representada por um conjunto de pontos no espaço que tenham maior integração entre si do que com o restante do mundo.

Outra questão importante é a forma como esse desenvolvimento é distribuído. Nesse contexto, alguns índices são usados, dentre os quais o índice de Gini, que mede a desigualdade existente na distribuição de indivíduos segundo a renda domiciliar per capita. Segundo Perobelli, Ferreira e Faria (2006) a disparidade regional é inerente ao processo de crescimento econômico e não é possível pensar em planos de desenvolvimento econômico que visem a equalização pura das regiões.

Desta monta, o presente estudo tem como objetivo analisar o padrão de associação espacial do desenvolvimento regional (PIB per capita) e da desigualdade de renda domiciliar per capita (índice de Gini) no estado do Paraná nos anos 2000 e 2010. Investiga-se assim, a autocorrelação espacial dos dados e possível formação de clusters de desenvolvimento nos municípios paranaenses. Além disso, este estudo diferencia-se dos demais trabalhos sobre o estado do Paraná, pelo uso de uma análise espacial bivariada, analisando clusters entre índice 
de Gini e índice de desenvolvimento humano municipal da educação, assim como PIB per capita e índice de desenvolvimento humano municipal da educação.

Além desta introdução, o trabalho divide-se em mais 4 seções. A próxima seção apresenta a fundamentação teórica. A terceira seção descreve a metodologia utilizada no trabalho. Em seguida, na quarta seção analisam-se os resultados obtidos por meio dos indicadores de desenvolvimento no estado do Paraná, assim como os resultados da AEDE. Por fim, na última seção são tecidas as principais conclusões deste estudo.

\section{REVISÃO DE LITERATURA}

A discussão da importância do capital humano para o crescimento econômico e aumento da renda per capita apresentam longa tradição na literatura econômica. Schultz $(1960,1961,1962)$ foi um dos principais economistas a enfatizar que o capital humano seria um elemento chave para o crescimento econômico, para o autor a acumulação deste fator seria a principal fonte deste crescimento no longo prazo.

Solow (1956) em seu modelo demonstra que a tecnologia é responsável pelo crescimento econômico sustentado no longo prazo, porém, a variável foi definida exógenamente (simplesmente especula-se uma taxa de crescimento do progresso técnico, sem explicar como de fato essa é gerada). Posteriormente, desenvolvem-se os chamados modelos de crescimento endógeno e estes ganham espaço na literatura econômica; tais modelos procuram endogeneizar o progresso tecnológico, explicando assim sua origem. No bojo desses, alguns autores colocaram o capital humano como o responsável pelo progresso técnico, inserindo-o na função de produção, como Lucas (1988) e Romer (1990).

Becker (1993), autor da teoria do capital humano, foi altamente influenciado pelos estudos de Schultz $(1960,1961,1962)$. O autor afirma que o indivíduo pode continuar investindo em sua formação, levando em conta o retorno que a continuidade desta proporcionará no futuro. Porém, ainda hoje é questionada a efetiva capacidade do capital humano em influenciar o crescimento econômico, como demonstrado em Nakabashi e Figueiredo (2008) e em Cangussu, Salvato e Nakabashi (2010), devido principalmente a problemas metodológicos; é fato que essa variável tem a capacidade de influenciar diversas outras variáveis micro e macroeconômicas.

Conforme Souza e Oliveira (2006) a produtividade está relacionada com o nível de escolaridade, o autor afirma que países que apresentam baixo nível de escolaridade também apresentam baixo nível de produtividade, sendo a educação um meio promotor de retornos crescentes para o setor produtivo e para o indivíduo. Nessa mesma linha, Nakabashi e Figueiredo (2008) afirmam que o capital humano pode afetar a renda per capita dos trabalhadores de várias maneiras (diretas e indiretas), como por exemplo, pela criação de tecnologia, tanto quanto pela facilitação do emprego de tecnologias (difusão) e não apenas sobre a produtividade marginal do trabalhador. Dado o exposto, o presente estudo busca analisar a relação do capital humano com desenvolvimento regional do Paraná. 
Cumpre destacar que o capital humano não é o único fator que influencia a dinâmica e desenvolvimento de uma determinada região, vários autores tentaram explicar o dinamismo de uma região a partir da renda urbana e outras variáveis. Perroux (1967) afirma que o crescimento ocorre em polos, desta forma é irregular no espaço, porém é dependente da economia nacional. O crescimento desses polos é influenciado ainda pelo crescimento de determinadas indústrias assim como o pelo surgimento de novas indústrias.

Outra teoria tradicional acerca do desenvolvimento regional fora desenvolvida por Myrdal (1957), a chamada teoria da causação circular cumulativa. Explica-se assim que fatores dentro de um determinado processo podem ser causa e efeito de outros fatores, fazendo com o que o desenvolvimento se torne circular e se acumule, sendo assim parecido com um ciclo vicioso. A teoria descreve que é necessário estudar como os fatores podem influenciar a estrutura da economia e como o sistema se comporta frente a mudanças exógenas, sustentando assim, o papel do estado no desenvolvimento econômico. Esses fatores podem ser tanto positivos quanto negativos, desta forma, a causação circular cumulativa poderia contribuir para discrepâncias regionais. $\mathrm{O}$ autor afirma ainda que com o tempo os fatores de produção poderiam se concentrar em determinadas regiões já historicamente mais desenvolvidas, sendo necessárias políticas publicas para equilibrar a concentração regional.

Outros autores ditos seminais contribuíram para o entendimento e refinamento das teorias sobre desenvolvimento regional. Hirschman (1958) afirma que teorias de crescimento tradicionais não são suficientes para explicar o desenvolvimento de determinadas regiões, pois o mesmo acontece de forma heterogênea dentro de um país, afirmando que a atividade produtiva pode se concentrar em determinadas regiões devido processos de complementariedade e aprendizagem. $\mathrm{O}$ autor ainda distingue o processo em países desenvolvidos e em subdesenvolvidos, nesses últimos os recursos são mais escassos, além de poupança e investimento, tornando o processo menos dinâmico.

Discute-se ainda a teoria da base de exportação, onde segundo North (1977) o desenvolvimento regional é relacionado à capacidade de exportação de determinada região. Jacobs (1969) afirma que o crescimento de determinada região está diretamente relacionado aos efeitos multiplicadores das exportações e importações. Os dois estariam intimamente relacionados e são possíveis devido à capacidade de especialização produtiva de determinada região. Deste modo, o aumento das exportações geraria emprego e aumento de renda em determinada região que acabaria por estimular a importação de determinados produtos, essa importação viabilizaria a produção e diversificação da produção, se o aumento dessa produção estiver condicionado ao aumento das exportações os efeitos se potencializam. Assim, o processo de desenvolvimento de uma região estaria intimamente ligado à capacidade de substituição das importações.

Isso posto, observa-se que ao longo do tempo estudos relacionados ao desenvolvimento regional se tornaram mais recorrentes na literatura econômica. Perobelli, Ferreira e Faria (2006), fazem uma análise da convergência espacial do PIB per capita no estado de Minas Gerais entre 1975-2003. Os autores revisam as várias teorias em torno do desenvolvimento, utilizam a análise exploratória de dados espaciais e um modelo de convergência para os municípios mineiros. Encontram clusters significativos AA - Alto-Alto - e BB - Baixo-Baixo - em determinadas regiões do estado e ainda fortalecimento dos clusters $\mathrm{AA}$ no período analisado. Em relação à convergência, os autores concluem que não

DRd - Desenvolvimento Regional em debate (ISSNe 2237-9029) 
houve convergência do PIB per capita no período 75-96, apresentando convergência apenas entre 96-2003.

Barreto, Almeida e Lima (2010) estudaram a convergência do PIB per capita no estado do Ceará, esses autores também utilizaram a AEDE. O estudo demonstrou convergência no período analisado, sendo 51 anos - à frente - o tempo necessário para que o nível de renda per capita atinja metade do nível do estado estacionário, demonstrando assim a grande desigualdade regional do estado. Além disso, os autores demonstraram que houve uma mudança da indústria para o interior do estado, confirmadas através de clusters AA, em detrimento de clusters BB na região metropolitana de Fortaleza e no litoral leste do estado.

Costa et. al. (2007) analisaram o comportamento espacial do índice de desenvolvimento humano em suas três dimensões (educação, longevidade e renda per capita) no Rio Grande do Norte, por meio da AEDE. O estudo permite concluir que existe dependência espacial dos dados, e que o padrão de desenvolvimento do estado está ligado a questões históricas do processo de urbanização do estado.

No caso do Paraná, Lima, Caldarelli e Camara (2014) analisam o desenvolvimento municipal no estado na década de 2000, utilizando AEDE e dados do Índice de desenvolvimento municipal da FIRJAN - IFDM - em suas três dimensões - Emprego e Renda, Educação e Saúde. Constataram concentração espacial e clusters de alto e baixo desenvolvimento em diferentes regiões do estado. Sendo, no geral, os clusters de alto desenvolvimento concentrados nas regiões: Norte Central, Oeste e Metropolitana de Curitiba, e os de baixo desenvolvimento nas regiões: Central e Leste do estado.

Os aludidos autores identificam um padrão de desenvolvimento econômico heterogêneo no Paraná, com clusters do tipo AA e BB, contudo não exploram as relações desses com indicadores educacionais ou de renda. Lázari (2014) através da AEDE analisa a educação e crescimento econômico no estado do Paraná entre 2000 e 2010, dispõem de variáveis como percentual da população com 25 anos ou mais com ensino superior completo, IDHM educação e PIB per capita. O estudo verifica uma autocorrelação positiva entre PIB per capita e as demais variáveis.

O presente artigo, com vistas a prospectar a relação entre as aglomerações de alto e baixo desenvolvimento no estado e suas causas, ou mesmo explorar seus condicionantes, investiga por meio da análise espacial bivariada a relação entre capital humano e desenvolvimento econômico. Assim, o estudo busca encontrar essa correlação a nível municipal, que se diferencia de uma análise estadual pelo fato da mobilidade dos fatores de produção ser maior entre as regiões. Pode-se, neste caso, encontrar as regiões do estado mais associadas espacialmente em relação ao capital humano. $\mathrm{O}$ estudo inova ao associar o capital humano com a desigualdade de renda do estado. De acordo com Lima (1980), os defensores da teoria do capital humano defendem a igualdade de oportunidades (acesso), pois a educação é uma variável que pode ser modificada e reestruturada com políticas educacionais, ao contrário das características inatas dos indivíduos como raça, classe social e origem geográfica.

Colman e Nixon (1981) afirmam que o PIB per capita mesmo apresentando algumas fraquezas é o indicador mais eficaz para medir o desenvolvimento alcançado por uma região, já que indicadores econômicos e sociais são altamente correlacionados com o nível do PIB 
per capita. Assim, para medir o nível de desenvolvimento humano utilizou-se a variável PIB per capita. Já para medida de desigualdade de renda foi utilizado o índice de Gini, que é o indicador mais amplamente utilizado e aceito pela literatura.

Em relação ao capital humano, foi utilizado como proxy o índice de desenvolvimento humano municipal - componente educação. Segundo Kroth e Dias (2012) na área macroeconômica, os dois maiores benefícios do capital humano são i) Crescimento do nível educacional favorece a produção de ideias, gerando inovações tecnológicas, que por sua vez originam novos produtos e melhoria nos processos produtivos. ii) $\mathrm{O}$ maior capital humano aumenta a produtividade dos indivíduos, possibilitando-lhes um maior volume de capital/tecnologia. Nakabashi e Figueiredo (2008) acreditam que o capital humano tanto medido por seu estoque como no fluxo podem afetar a renda do trabalhador.

A proxy utilizada foi escolhida por ser um índice composto tanto de variáveis de estoque como de fluxo. Ou seja, analisa tanto o aumento do número de trabalhadores qualificados, como analisa o maior nível de formação desses trabalhadores. A escolha também se deve por ser um índice facilmente comparável, já que existem estatísticas de IDHM disponíveis para praticamente todos os estados.

A utilização de proxies para o capital humano é muito discutida na literatura e dependendo da variável utilizada, não demonstra causalidade entre capital humano e crescimento econômico, como ponderado em Kroth e Dias (2012). Nakabashi e Figueiredo (2008) utilizam hipóteses em que o capital humano pode afetar a renda do trabalhador de acordo com as variáveis: Investimento em capital humano por trabalhador (fluxo), estoque por trabalhador (que ajuda na facilitação no emprego de tecnologias) e investimento em criação de tecnologia. O IDHME foi utilizado como Proxy, pois, é um índice que leva em consideração tanto o estoque de capital humano (\% de pessoas de 18 anos ou mais de idade com ensino fundamental completo; \% de jovens de 15 a 17 anos com ensino fundamental completo e; \% de jovens de 18 a 20 anos com ensino médio completo), como o fluxo (\% de crianças de 5 a 6 anos frequentando escola; \% de jovens de 11 a 13 anos frequentando os anos finais do ensino fundamental;). Sendo ainda essa variável de fácil comparação, já que os dados estão disponíveis para praticamente todos os estados brasileiros.

\section{METODOLOGIA}

\subsection{Base de Dados}

Os indicadores socioeconômicos utilizados foram: $\mathrm{O}$ índice de unidades atendidas de esgoto ${ }^{4}$ obtido junto a SANEPAR, índice do valor adicionado setorial e PIB, obtidos junto ao IBGE (filtrados por região do estado). Já os dados municipais utilizados na análise

\footnotetext{
${ }^{4} \mathrm{O}$ índice aborda as unidades atendidas, sendo uma unidade atendida todo imóvel, ou subdivisão independente do imóvel, dotado de pelo menos um ponto de água, identificável, como unidade autônoma para efeito de cadastramento e cobrança de tarifa.
}

DRd - Desenvolvimento Regional em debate (ISSNe 2237-9029)

v. 6, n. 3, p. 193-215, nov. 2016. 
exploratória de dados espaciais (AEDE) foram: O Índice de desenvolvimento humano municipal - componente educação ${ }^{5}$ dos anos 2000 e 2010 assim como índice de Gini ${ }^{6}$, e população total em domicílios particulares permanentes (para cálculo do PIB per capita) para o mesmo período, obtidos junto ao ATLAS do desenvolvimento, e PIB per capita dos anos 2000 e 2010 obtido junto ao IBGE.

Cumpre destacar que no conjunto de dados selecionados o IDH municipal componente educação - foi utilizado neste estudo como proxy para capital humano. Conquanto seja razoável a utilização deste indicador, no escopo deste estudo, salienta-se a relevância de uma proxy qualitativa para tanto, nos termos de Nakabashi e Figeiredo (2008). Neste estudo, empreendeu-se um esforço para a definição e utilização de uma proxy neste sentido, contudo, verificou-se que a definição dessa variável envolveria procedimentos metodológicos que estariam muito além do escopo de abrangência deste, assim como comprometeriam a questão da objetividade do artigo e limitação de tamanho. Desta feita, optou-se pela utilização do IDH dos termos já descritos, procedimento amplamente utilizado na literatura acerca de desenvolvimento e capital humano e que não comprometem as conclusões deste artigo.

\subsection{ANÁLISE EXPLORATÓRIA DE DADOS ESPACIAIS}

Anselin (1998) descreve o AEDE como um conjunto de técnicas, para descrever e visualizar espacialmente distribuições, localizar distribuições atípicas (outliers), descobrir padrões de distribuição espacial (clusters), sugerir diferentes regimes espaciais e outras formas de instabilidade espacial ou não estacionariedade espacial. Sendo a ferramenta mais importante na AEDE a autocorrelação espacial, o fenômeno onde similaridades locacionais (proximidade espacial) é acompanhada por valor de similaridade (correlação).

Segundo Anselin (1998), a autocorrelação espacial pode ser conceituada a partir de duas perspectivas principais, a das ciências físicas e a das ciências sociais. Seguindo a classificação de Cressie's (1993) na autocorrelação espacial das ciências sociais, as localizações espaciais são pontos discretos ou unidades de área e os dados espaciais são conceituados como uma única realização de um processo estocástico espacial, semelhante à analise adotada na análise de séries temporais, diferente da perspectiva geoestatística que considera as observações espaciais como uma amostra de pontos contínuos subjacentes na superfície. Essencial na análise de estrutura de dados é o conceito de uma matriz de pesos espaciais que expressa o arranjo espacial (topologia, contiguidade) dos dados e constitui o ponto de partida para apontar qualquer teste estatístico ou modelo por extenso.

Utilizou-se no trabalho as estatísticas I de Moran Global e Local. Segundo Câmara e Carvalho (2004) a primeira é utilizada para descrever a estrutura de correlação espacial que

\footnotetext{
${ }^{5}$ O IDHM (índice de desenvolvimento humano municipal) é formado por três índices que abordam dimensões do desenvolvimento humano, educação, longevidade e renda. Varia de 0 a 1 e apresenta 5 faixas de desenvolvimento humano. O utilizado foi o IDHM da educação.

${ }^{6}$ Seu valor varia de 0 (quando a renda domiciliar per capita é igual para todos os indivíduos) a 1 quando a desigualdade é máxima. $\mathrm{O}$ universo de indivíduos limita-se àqueles que possuem domicílios particulares permanentes.
}

DRd - Desenvolvimento Regional em debate (ISSNe 2237-9029)

v. 6, n. 3, p. 193-215, nov. 2016. 
melhor descreva os dados. Já a segunda é utilizada quando se dispõe de grande número de áreas, sendo muito provável a existência de diferentes regimes de correlação espacial em diferentes sub-regiões. De acordo com Cliff e ORD (1981) a estatística I de Moran é dada por:

$$
I=\left(\frac{n}{S o}\right)\left(\frac{z^{\prime} W z}{z^{\prime} Z}\right)
$$

Onde $n$ representa o número de áreas; $z$ denota os valores da variável de interesse padronizado; $W z$ representa os valores médios da variável de interesse padronizada nos vizinhos, definido segundo uma matriz de ponderação espacial $W$. Sendo os elementos da diagonal $W_{i i}$ igual a 0 , enquanto os elementos $W_{i j}$ indicam a forma com que a região $i$ está espacialmente conectada com a região $j$. So é uma escalar, igual à soma de todos os elementos de W. Assim, conforme Almeida, Perobelli e Ferreira (2008) estatística I de Moran fornece a indicação formal do grau de associação linear entre os vetores de valores observados de uma variável de interesse no tempo e a média ponderada dos valores da vizinhança, ou as defasagens espaciais $W_{z}$. Valores de $I$ maiores (ou menores) do que o valor esperado $E(I)=$ $-\frac{1}{n-1}$ significa que há autocorrelação positiva (ou negativa).

Segundo Lima, Caldarelli e Camara (2014), por se tratar de uma estatística, é necessário verificar sua significância. Isso pode ser feito através de um teste de hipóteses, onde a hipótese nula é de ausência de autocorrelação espacial e a hipótese alternativa é de presença de autocorrelação espacial. Assim, supõe-se que a estatística I seja normalmente distribuída, essa distribuição é construída através do pressuposto da aleatorização ${ }^{7}$. Como regra de decisão utiliza-se o pseudo valor-p que indica a probabilidade de se rejeitar a hipótese nula sendo ela verdadeira. Se o pseudo valor-p for menor que determinado nível de significância rejeita-se a hipótese nula.

Para visualização da estatística I de Moran pode ser utilizado o diagrama de dispersão de Moran (Moran scatterplot). O diagrama de dispersão de Moran é capaz de mostrar a correlação linear entre $y$ (variável em análise), sendo $y=y-\bar{y}$ e $W y$ (variável em análise defasada espacialmente), através do gráfico de duas variáveis. Segundo Almeida, Perobelli e Ferreira (2008) trata-se de uma representação do coeficiente de regressão. O diagrama é dividido nos 4 quadrantes $(\mathrm{AA}, \mathrm{BB}, \mathrm{AB} \text { e } \mathrm{BA})^{8}$, como mostra a Figura 1.

\footnotetext{
${ }^{7}$ Os valores observados da variável em análise são aleatoriamente realocados para as diversas regiões. Após a realocação, a estatística de teste é calculada para uma dessas realocações. Obtendo assim, uma distribuição de referência empírica.

${ }^{8}$ Sendo $\mathrm{A}=$ Alto e $\mathrm{B}=$ Baixo, ou seja, $\mathrm{AA}=$ Alto-Alto; $\mathrm{BB}=$ Baixo-Baixo; $\mathrm{AB}=$ Alto-Baixo e $\mathrm{BA}=\mathrm{Baixo}-$ Alto.
} 
Figura 1 - Ilustração do Diagrama de dispersão de Moran.

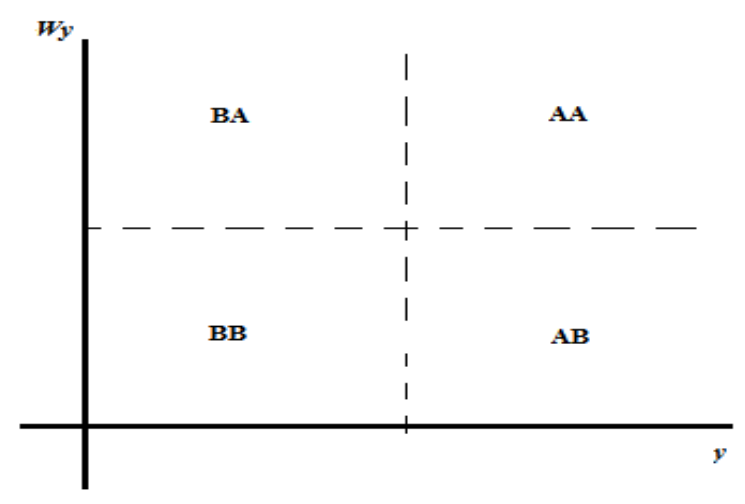

Fonte: Elaborado pelos autores.

Anselin (1998) propõe o índice de Moran local, ou LISA (Local Indicators of Spatial Association), sendo uma decomposição do indicador global de autocorrelação na contribuição local, servindo assim segundo Lima, Caldarelli e Camara (2014) para responder questões de associação local nos dados. O LISA deve satisfazer dois critérios: primeiro, para cada observação o LISA deve oferecer uma indicação de Clusters espaciais significantes de valores similares em torno da observação, segundo, a soma dos LISA'S para todas as observações é proporcional ao indicador de associação espacial global. A contribuição local de cada observação é dividida em quatro categorias (AA, BB, AB, e BA), ou seja, AA, significa que a região i é alta em relação à média e seu vizinho j também é alto. De acordo com Anselin (95) o indicador é dado por:

$$
I_{i}=z_{i} \sum_{j=1}^{n} w_{i j} z_{j}
$$

Onde $z_{i}$ é a variável analisada padronizada da região $i, z_{j}$ é a variável analisada no seu vizinho $j$ e $w_{i j}$ é a matriz de peso espacial. Assim como no caso do I de Moran global, o resultado da estatística depende de seu valor em relação a esperança matemática. Além disso, deve-se verificar sua significância ${ }^{9}$, através do pressuposto de aleatorização e em seguida plotá-los no mapa para análise dos clusters.

O trabalho utilizou ainda a estatística I de Moran bivariado, ou seja, um índice em que são utilizadas duas variáveis. Segundo Almeida (2004), o índice serve para identificar se valores de uma variável em certa região, apresenta associação com outra variável, nas suas regiões vizinhas.

Para definição da matriz de pesos espaciais $(W)$, utilizou-se a matriz Rainha (Queen) por ser mais comumente usada. As matrizes de pesos espaciais são definidas através da contiguidade com sua vizinhança. A matriz de pesos espaciais é utilizada com o objetivo de capturar os efeitos de contiguidade e vizinhança sobre os dados, através de ponderações, ou seja, a variável observada em cada região recebe uma ponderação, quando fizer vizinhança com a região analisada.

Para análise dos dados, utilizou-se o software GEODA.

${ }^{9}$ Sendo H0: Ausência de autocorrelação espacial local e HA: Presença de autocorrelação espacial local. 


\section{RESULTADOS E DISCUSSÃO}

\subsection{DESENVOLVIMENTO NO ESTADO DO PARANÁ.}

Em 2010, a população do estado do Paraná, segundo o IBGE, era de $10.444 .526 \mathrm{em}$ seus 399 municípios. De acordo com Lima, Caldarelli e Camara (2015) o estado apresenta grande heterogeneidade espacial com relação ao seu desenvolvimento econômico. Com relação à evolução dos indicadores sintéticos de desenvolvimento humano no estado, a Figura 2 mostra a evolução do índice de Gini, e IDHM para os anos de 2000 e 2010.

De acordo com Figura 2, o índice de Gini diminui de 0,6 para 0,53. Ou seja, houve redução da desigualdade de renda domiciliar per capita no estado como um todo. Além disso, o IDHM aumentou em todas as suas dimensões, mostrando que houve um aumento do desenvolvimento no estado. O IDHM geral neste ano foi de 0,749 e classifica o estado como de alto índice de desenvolvimento humano. Porém, apesar de o IDHM da educação ter aumentado aproximadamente $28 \%$, ainda é o mais baixo dentre as três dimensões, sendo o único classificado como médio.

Cumpre mencionar, que os indicadores sintéticos de desenvolvimento humano do Paraná mostrados na Figura 2 representam a média do estado, em que a heterogeneidade destes e a concentração espacial dos mesmos devem ser mencionadas para que a análise (Figura 2) não seja viesada.

Figura 2 - Evolução de indicadores entre 2000 e 2010.

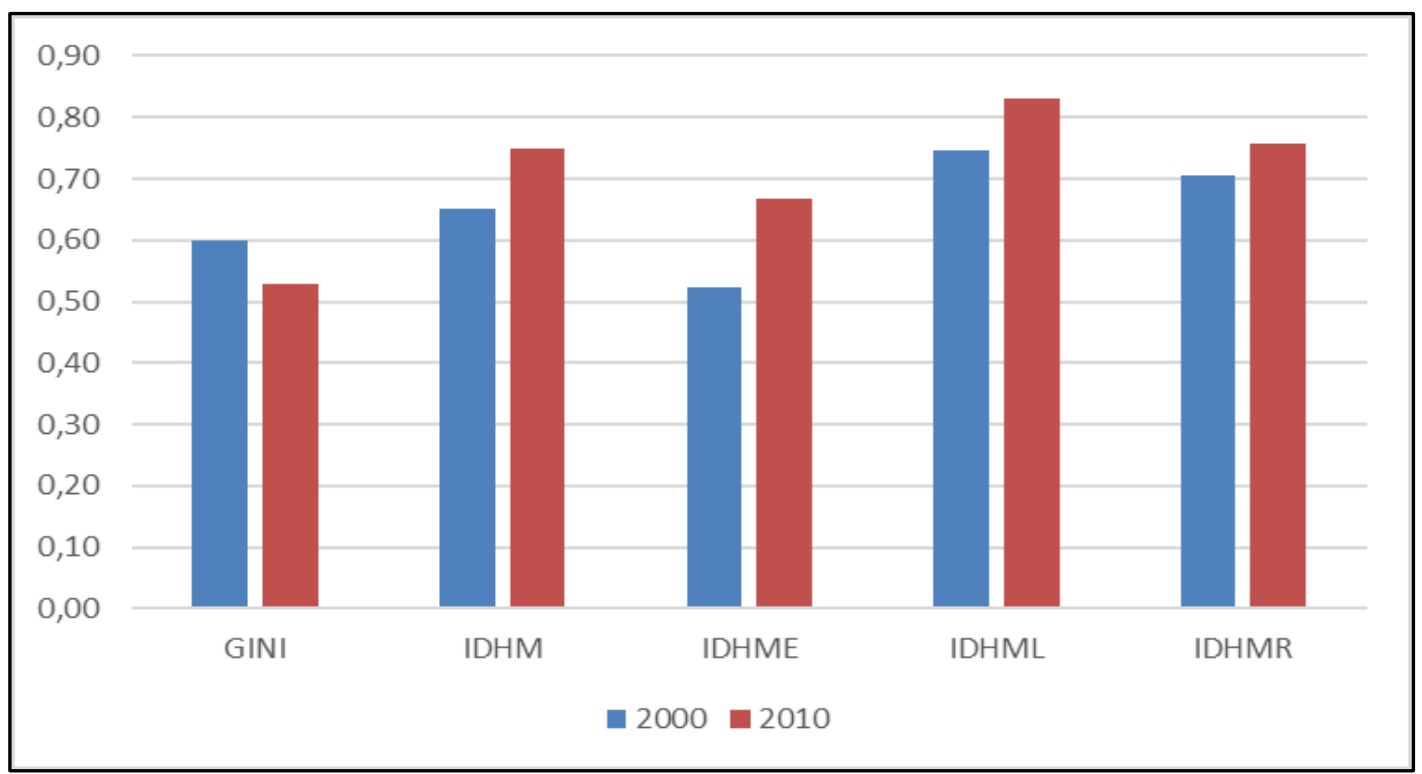

Fonte: Elaborado pelos autores a partir dos dados do ATLAS. 
Outros dados importantes para avaliação do progresso do desenvolvimento e qualidade de vida dos paranaenses são os de saneamento. Nesse caso, utilizou-se o número de unidades atendidas de esgoto nas regiões paranaenses. A Tabela 1 mostra a evolução do número de unidades atendidas em relação ao fornecimento de esgoto. Infere-se que no estado como um todo houve um aumento de $90,16 \%$ no provimento deste serviço. Importante frisar que as regiões com maior aumento foram Centro ocidental Paranaense, Noroeste Paranaense e Sudeste Paranaense, regiões de pouca importância econômica e que apresentam os menores indicadores de produto e renda. Assim, a evolução na década parece incluir regiões mais pobres melhorando a qualidade de vida das pessoas, na média.

Para verificar a heterogeneidade econômica entre as regiões do Paraná, utilizou-se os índices de valor adicionado setorial e PIB a preços de mercado, obtidos juntos ao IBGE e dispostos nas Tabela 2 e Tabela 3.

Tabela 1 - Unidades atendidas de Esgoto nos anos 2000 e 2010 no estado do Paraná.

\begin{tabular}{lcc}
\hline \multicolumn{1}{c}{ Região } & \multicolumn{2}{c}{ Esgoto (em unidades domiciliares) } \\
\cline { 2 - 3 } & 2000 & 2010 \\
\cline { 2 - 3 } Centro Ocidental Paranaense & 15.564 & 34.357 \\
Centro Oriental Paranaense & 68.554 & 138.798 \\
Centro-Sul Paranaense & 27.359 & 47.718 \\
Metropolitana de Curitiba & 437.588 & 819.139 \\
Noroeste Paranaense & 39.849 & 95.116 \\
Norte Central Paranaense & 242.610 & 422.741 \\
Norte Pioneiro Paranaense & 54.150 & 85.050 \\
Oeste Paranaense & 86.828 & 180.752 \\
Sudeste Paranaense & 17.562 & 38.266 \\
Sudoeste Paranaense & 25.340 & 69.015 \\
\hline
\end{tabular}

Fonte: SANEPAR.

Concernente as variáveis econômicas, a Tabela 2 apresenta a distribuição do valor adicionado do PIB - por setor - nas regiões do estado do Paraná para o ano de 2000.

Tabela 2 - Valor adicionado por setor e PIB a preços de mercado em percentual no ano 2000.

\begin{tabular}{lcccc}
\hline \multicolumn{1}{c}{ Região } & \multicolumn{2}{c}{ Valor Adicionado } & $\begin{array}{c}\text { PIB - Preço de } \\
\text { mercado \% }\end{array}$ \\
\cline { 2 - 4 } & Agropecuária & Indústria & Serviços & 2,95 \\
\hline Centro Ocidental & 8,98 & 1,36 & 2,82 & 6,18 \\
Centro Oriental Paranaense & 10,13 & 7,31 & 5,07 & 3,34 \\
Centro-Sul Paranaense & 7,76 & 2,80 & 2,95 & 42,64 \\
Metropolitana de Curitiba & 5,97 & 46,37 & 46,25 & 4,23 \\
Noroeste Paranaense & 8,53 & 2,65 & 4,35 & 17,08 \\
Norte Central Paranaense & 15,14 & 14,02 & 18,82 & 3,44 \\
Norte Pioneiro Paranaense & 6,79 & 2,29 & 3,49 & 13,21 \\
Oeste Paranaense & 18,12 & 17,68 & 10,38 & 2,39 \\
Sudeste Paranaense & 7,20 & 1,79 & 1,98 & 4,53 \\
Sudoeste Paranaense & 11,38 & 3,71 & 3,91 & 100 \\
Total & 100 & 100 & 100 & \\
\hline
\end{tabular}

Fonte: IBGE. 
Em termos da produção e sua distribuição espacial (Tabela 2) pode-se observar que essa variável no estado está altamente concentrada nas regiões Metropolitana de Curitiba, Norte Central Paranaense e Oeste Paranaense, que em conjunto são responsáveis por 73,07\% da produção do Paraná; destaque especial para a região de Curitiba que sozinha é responsável por $42,64 \%$ da produção do estado. O ano de 2010 segue o mesmo padrão, com uma estrutura produtiva concentrada nas três regiões citadas. Ademais, o setor menos concentrado do estado é o agropecuário, onde as três maiores regiões produtoras, no ano 2010 foram responsáveis por apenas $35,87 \%$ do total.

Relativo ao ano de 2010, a Tabela 3 apresenta a distribuição do valor adicionado do PIB - por setor - nas regiões do estado.

Tabela 3 - Valor adicionado por setor e PIB a preços de mercado em percentual no ano 2010.

\begin{tabular}{lcccc}
\hline \multicolumn{1}{c}{ Região } & \multicolumn{3}{c}{ Valor Adicionado } & $\begin{array}{c}\text { PIB - Preço de } \\
\text { mercado \% }\end{array}$ \\
\cline { 2 - 4 } & Agropecuária & Indústria & Serviços & 2,57 \\
Centro Ocidental & 5,84 & 1,65 & 2,53 & 6,11 \\
Centro Oriental Paranaense & 11,26 & 6,73 & 5,17 & 3,06 \\
Centro-Sul Paranaense & 6,56 & 2,69 & 2,75 & 44,31 \\
Metropolitana de Curitiba & 8,56 & 47,98 & 47,46 & 4,75 \\
Noroeste Paranaense & 11,09 & 3,77 & 4,33 & 16,65 \\
Norte Central Paranaense & 13,52 & 14,08 & 18,16 & 3,37 \\
Norte Pioneiro Paranaense & 8,89 & 2,16 & 3,16 & 12,12 \\
Oeste Paranaense & 15,81 & 15,12 & 10,34 & 2,33 \\
Sudeste Paranaense & 7,52 & 1,38 & 2,05 & 4,74 \\
Sudoeste Paranaense & 10,96 & 4,43 & 4,05 & 100 \\
Total & 100 & 100 & 100 & \\
\hline
\end{tabular}

Fonte: IBGE

O ano de 2010 segue o mesmo padrão de valor adicionado por setores observado para 2000, com uma estrutura produtiva concentrada nas três regiões citadas. Ademais, o setor menos concentrado do estado é o agropecuário, onde as três maiores regiões produtoras são responsáveis por apenas $40,59 \%$ do total.

Para o período analisado (2000-2010) observa-se que o estado do Paraná avançou em vários aspectos do desenvolvimento, apesar de ainda ser um estado altamente concentrador da atividade econômica. Com relação à concentração de renda, vários municípios do estado apresentam um índice de Gini superior ao estadual, demostrando assim a heterogeneidade dos municípios paranaenses. A próxima subseção fará uma análise espacial univariada do índice de Gini, PIB per capita e índice municipal de desenvolvimento humano componente educação (proxy para capital humano) dos municípios paranaenses, analisando a autocorrelação espacial nos munícipios paranaenses e também definindo regiões de desigualdade (clusters). Na subseção 4.3 analisa-se os mapas da estatística LISA. Já na última subseção faz-se ainda uma análise bivariada entre o índice de Gini e índice de desenvolvimento humano municipal da educação, assim como PIB per capita e índice de desenvolvimento humano municipal da educação, analisando se existe autocorrelação espacial entre estas variáveis. 


\subsection{DE MORAN GLOBAL E DIAGRAMA DE DISPERSÃO DE MORAN.}

Para analisar a autocorrelação espacial, utiliza-se primeiramente o I de Moran, com seus respectivos valores esperados, desvios padrão e pseudo valor-p, para as variáveis GINI (índice de Gini), IDHME (índice de desenvolvimento humano municipal - componente educação), e PIBPC (PIB per capita) na Tabela 4. Em seguida, a Figura 3 mostra os diagramas de dispersão de Moran para as variáveis GINI, PIBPC e IDHME.

Tabela 4 - I de Moran, Valor Esperado, Desvio Padrão e Pseudo-Valor P.

\begin{tabular}{llcclcccc}
\hline & \multicolumn{9}{c}{2000} & \multicolumn{3}{c}{2010} \\
\cline { 2 - 9 } & I de Moran & VE & DP & $\begin{array}{l}\text { Pseudo } \\
\text { valor-p }\end{array}$ & I de Moran & VE & DP & $\begin{array}{c}\text { Pseudo } \\
\text { valor-p }\end{array}$ \\
\hline GINI & 0,2765 & $-0,0025$ & 0,0319 & 0,001 & 0,3542 & $-0,0025$ & 0,0312 & 0,001 \\
IDHME & 0,5004 & $-0,0025$ & 0,0301 & 0,001 & 0,3994 & $-0,0025$ & 0,0311 & 0,001 \\
PIBPC & 0,1006 & $-0,0025$ & 0,0295 & 0,006 & 0,0442 & $-0,0025$ & 0,0274 & 0,052 \\
\hline
\end{tabular}

Elaborado pelos autores a partir dos dados do IBGE e ATLAS.

Nota: Pseudo-significância baseada em 999 permutações aleatórias.

Figura 3 - Diagramas de dispersão de Moran para as variáveis analisadas.

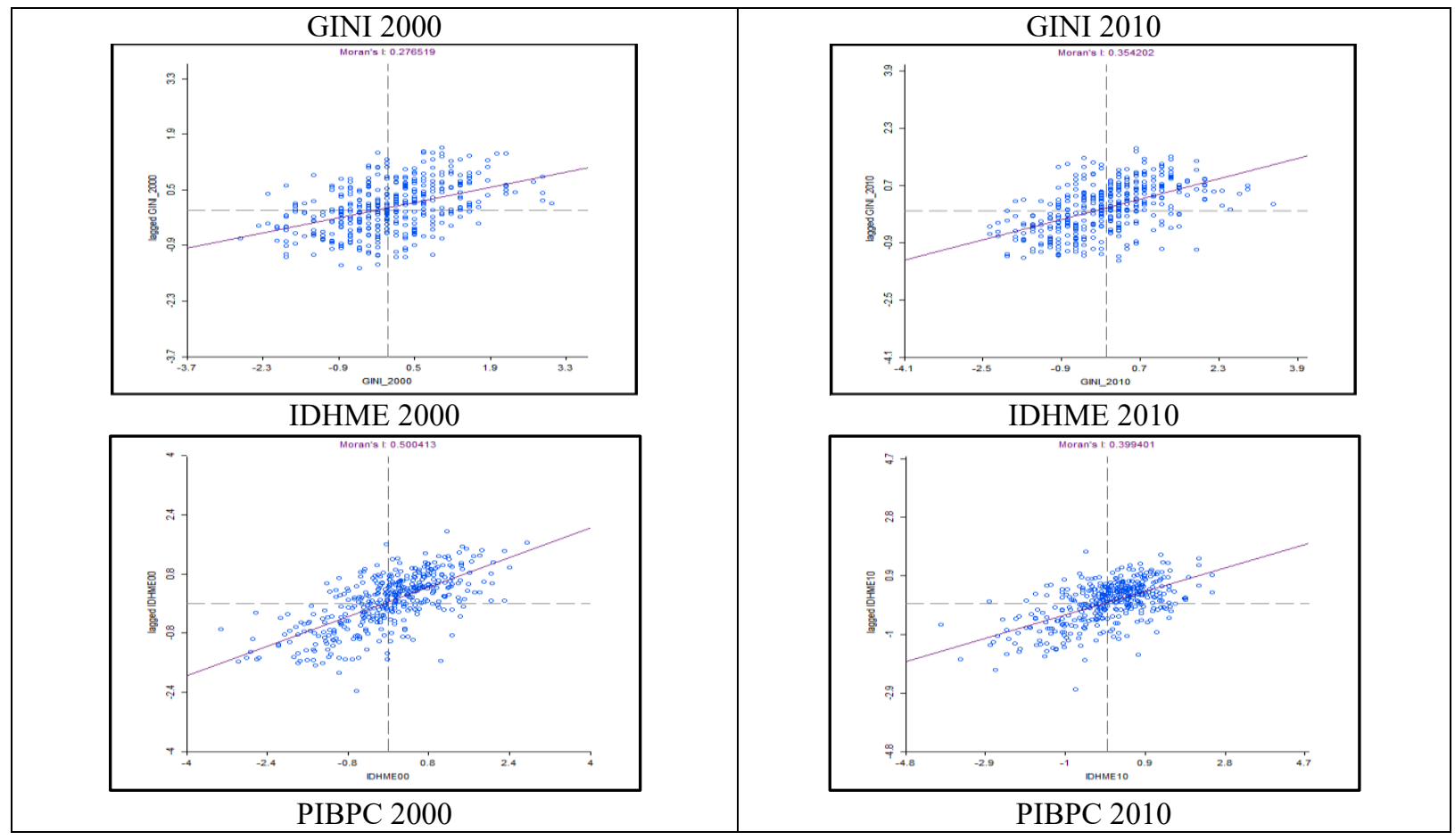




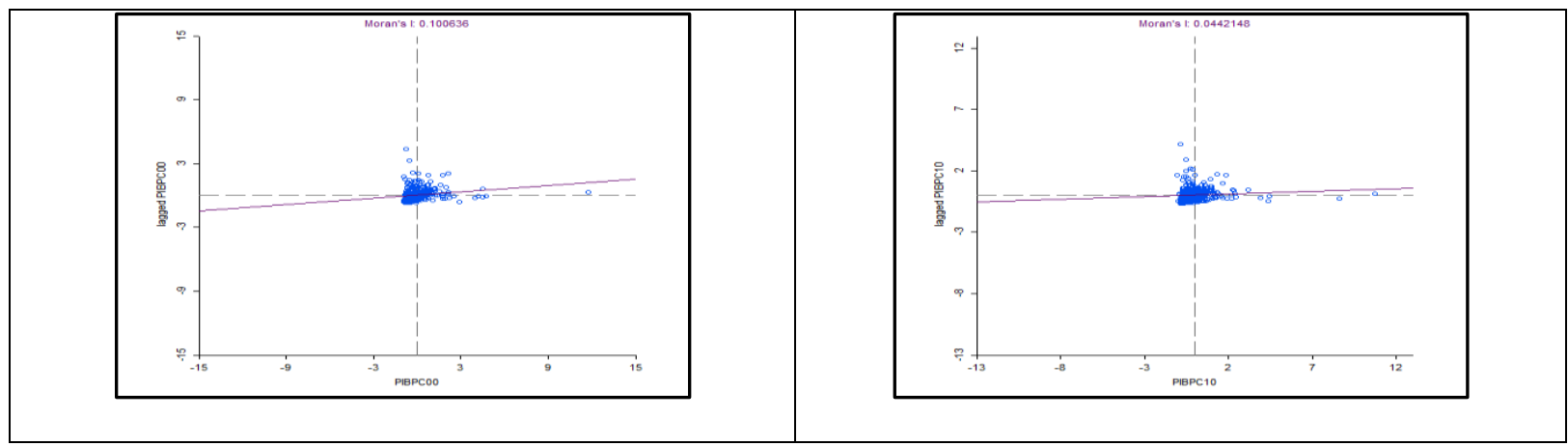

Fonte: Elaborado pelos autores a partir dos dados do IBGE E ATLAS.

Como mostra a Tabela 4, o I de Moran é maior que o valor esperado em todas as variáveis indicando assim, associação espacial positiva nos dados. Além disso, os valores são estatisticamente significativos, sendo o maior pseudo valor-p ocorrido na variável PIBPC no ano 2010.

Concernente à análise dos diagramas de dispersão de Moran, há uma confirmação de autocorrelação nos dados, sendo a reta positivamente inclinada quando os dados apresentam autocorrelação positiva e negativamente inclinada quando apresentam autocorrelação negativa. A autocorrelação positiva significa que os municípios de baixo (alto) valor da variável em relação à média são cercados por municípios também de baixo (alto) valor da variável em relação à média. Já a autocorrelação negativa significa que municípios de baixo (alto) valor da variável em relação à média são cercados por municípios de alto (baixo) valor da variável em relação à média. Assim, GINI, IDHME e PIBPC mantém seu padrão de associação espacial global na década, mantendo a maioria dos municípios nos quadrantes BB e AA, concentrando regiões mais e menos desenvolvidas. Cabe destacar que a variável PIBPC apesar de manter seu padrão de associação espacial durante a década, apresenta diminuição da inclinação da reta, demonstrando diminuição de autocorrelação espacial nos dados.

Com isso, a estatística global mostra que existe autocorrelação tanto na desigualdade da renda per capita (GINI), desenvolvimento (PIB per capita) e no capital humano (IDHME). Estes resultados corroboram que tais indicadores apresentam uma distribuição heterogênea no estado com padrões de concentração e associação espacial. Para analisar as áreas de concentração dessas variáveis espacialmente (padrão de associação espacial local), utilizou-se a estatística LISA.

\subsection{LISA}

Segundo Le Gallo e Ertur (2003) a estatística Lisa baseia-se no I de Moran local. Assim, essa estatística analisa os padrões de associação espacial significantes estatisticamente. A melhor maneira de visualizar estas associações se dá na forma de mapas. As Figuras 4, 5 e 6, mostram os mapas dos clusters para as variáveis: GINI, PIBPC e IDHME para os anos de 2000 e 2010. De acordo com Lima, Caldarelli, e Camara (2014), são a combinação da informação do diagrama de dispersão de Moran e a informação de 
significância das medidas de associação local $I_{i}$. Os mapas ilustram clusters em quatro categorias de associação espacial, estatisticamente significativos.

Figura 4 - Clusters para a variável Índice de Gini.

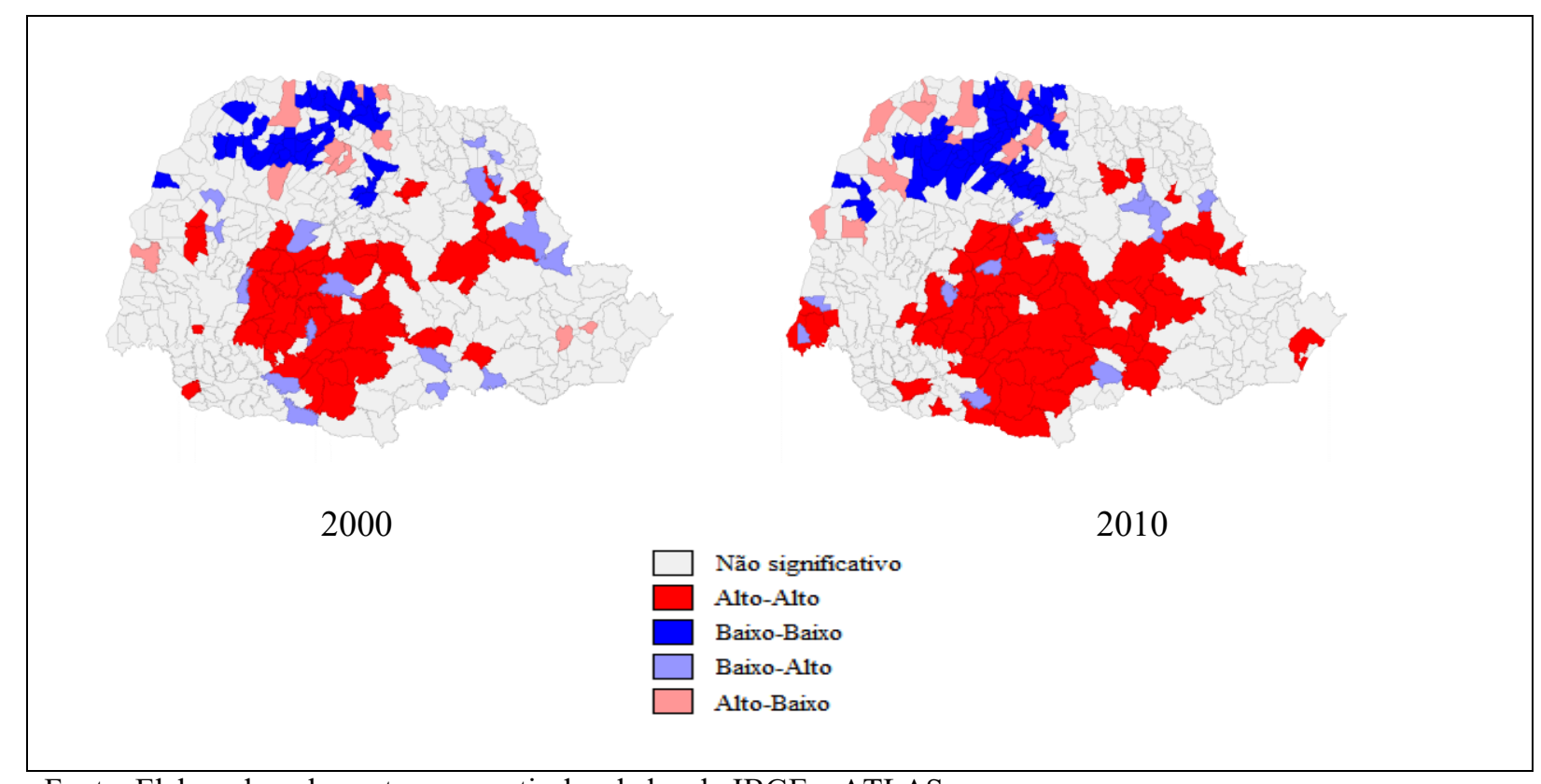

Fonte: Elaborado pelos autores a partir dos dados do IBGE e ATLAS

Em relação a variável GINI, evidencia-se a formação de todos os tipos de Clusters, com destaque para os $\mathrm{BB}$ e principalmente AA. Isso significa que municípios com alto (baixo) índice de Gini em relação à média são cercados por municípios com alto (baixo) índice de Gini em relação à média, ou seja, munícipios com alta desigualdade são cercados por outros munícipios com alta desigualdade. Ademais, os clusters BB e AA aumentaram durante período analisado, indicando um aumento da concentração espacial da desigualdade de renda nos municípios paranaenses. No total 56 municípios situaram-se em regiões de clusters BB em 2010, as regiões desses clusters foram principalmente: Norte Central e Noroeste Paranaense. Já os clusters AA (65) em 2010 situaram-se nas regiões: Oeste, CentroSul, Sudeste e Centro Oriental Paranaense. 
Figura 5 - Clusters para a variável PIB per capita.

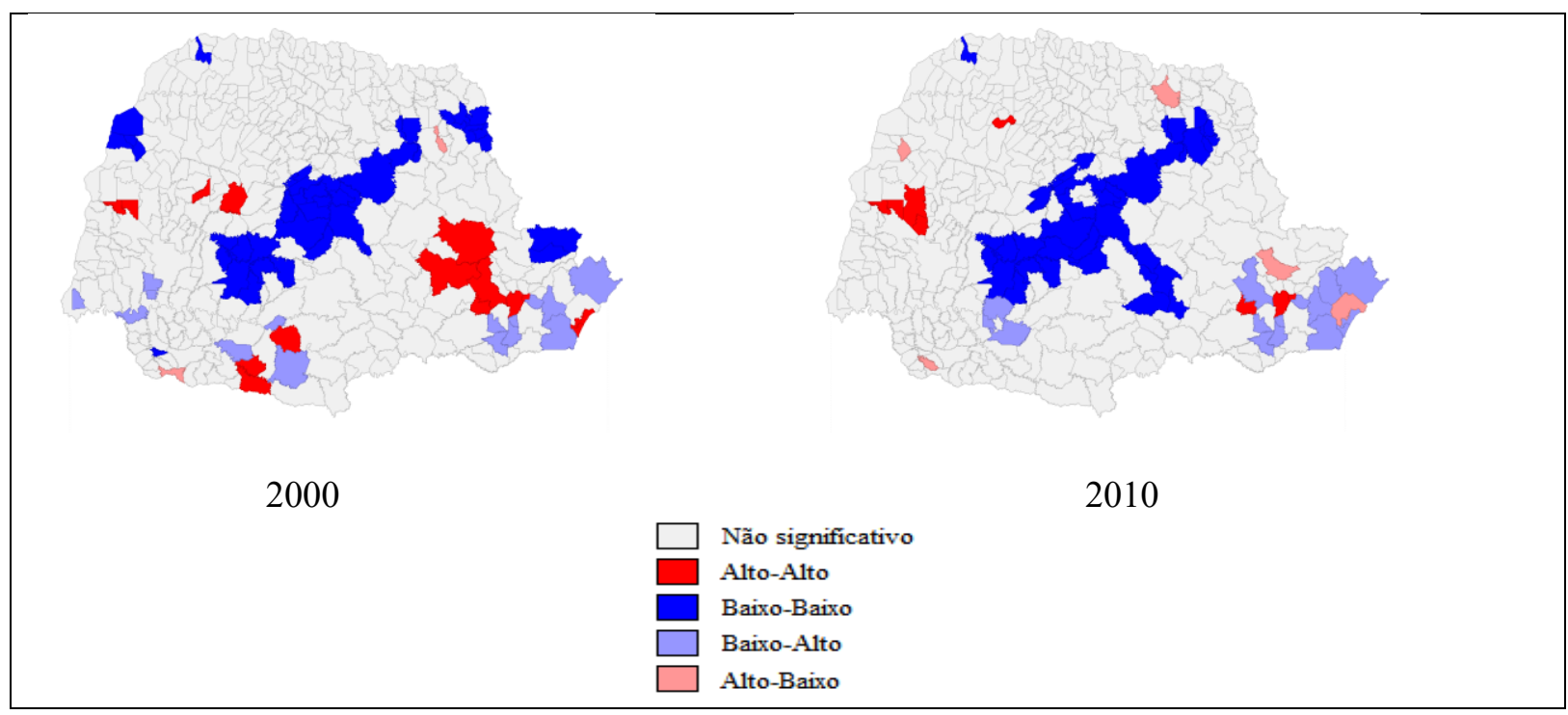

Fonte: Elaborado pelos autores a partir dos dados do IBGE e ATLAS.

A variável PIB per capita, por sua vez, demonstra estar menos autocorrelacionada espacialmente, com menor número de clusters $\mathrm{AA}$ e $\mathrm{BB}$, confirmando resultado presente no diagrama de dispersão de Moran. Regiões AA (15) em 2000 passam para (8) em 2010. Regiões BB também passam a diminuir no período analisado, passando de 42 em 2000 para 39 em 2010. Já as regiões BA se mantém com 15 municípios e as regiões $A B$ passam de 2 municípios em 2000 para 5 em 2010. Nesse caso, em 2010 a variável passa a ser a menos autocorrelacionada do estado, porém, por outro lado, perde algumas de suas regiões mais desenvolvidas, mantendo um alto número de regiões subdesenvolvidas (39) que devem receber maior atenção no sentido de políticas públicas, ademais observam-se mais regiões autocorrelacionadas negativamente, indicando outliers.

Figura 6 - Clusters para a variável IDHME.

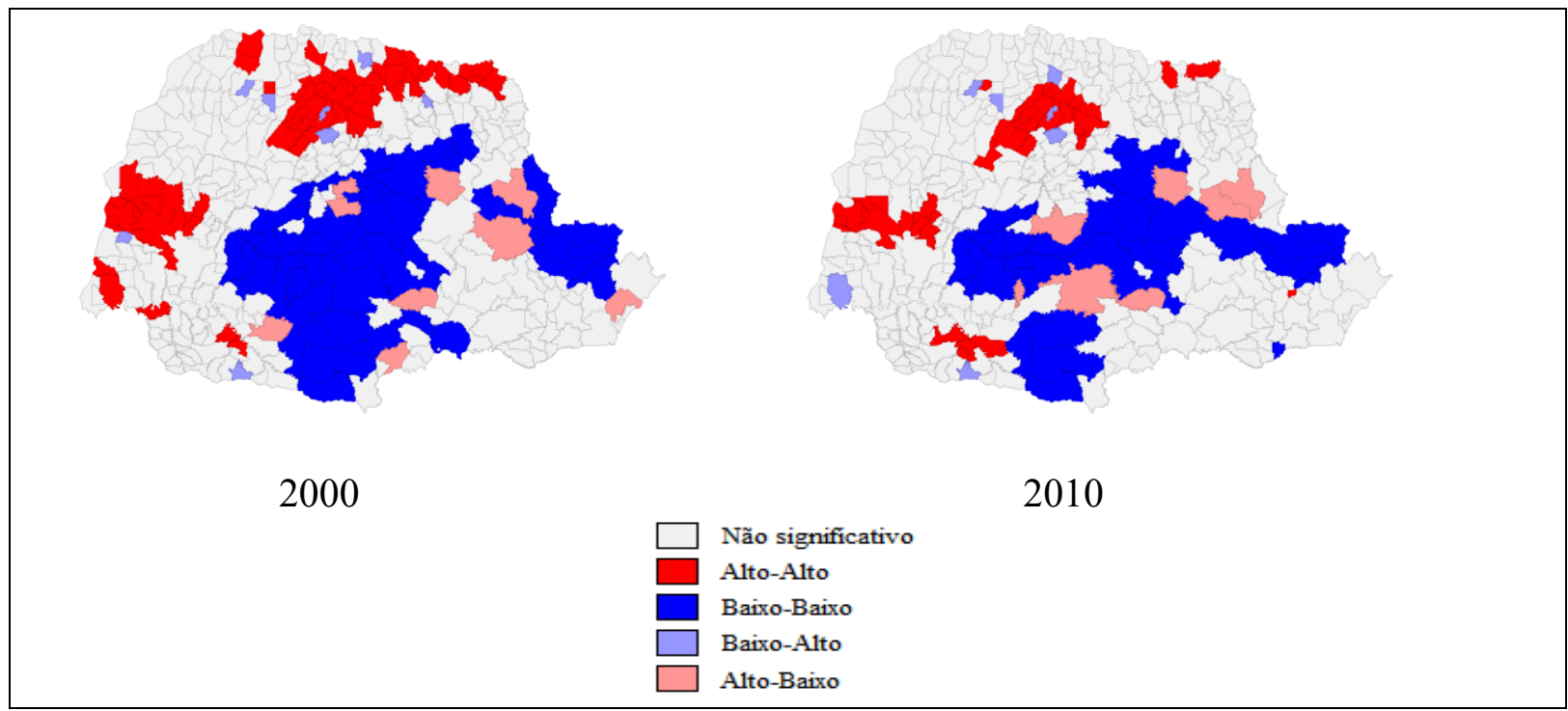

Fonte: Elaborado pelos autores a partir dos dados do IBGE e ATLAS.

DRd - Desenvolvimento Regional em debate (ISSNe 2237-9029) 
Na figura 6 mostram-se os clusters da variável IDHME nos municípios Paranaenses. Educação por si só, já é uma variável que gera inúmeras externalidades, Barros e Mendonça (1998) afirmam que os investimentos em educação não apenas influenciam as condições de vida daqueles que se educam, mas também gera uma série de externalidades para aqueles que os rodeiam.

É interessante frisar, que munícipios pertencentes aos clusters AA diminuíram de 2000 para 2010 passando de 68 para 43 e os pertencentes a BB também, passando de 61 em 2000 para 48 em 2010. Os munícipios de baixo capital humano que são cercados por outros municípios de baixo capital humano em sua maioria estão localizados nas mesmas "faixas" de regiões subdesenvolvidas em PIBPC e GINI e concentram-se em 2010, principalmente nas regiões: Centro Oriental, Metropolitana de Curitiba, Centro Sul, Oeste e Sudeste Paranaense. Já as os clusters de municípios AA se concentraram principalmente nas regiões: Norte Pioneiro, Norte Central, Oeste, Sudoeste Paranaense.

Assim, as figuras mostram que existe demasiada autocorrelação nos dados, assim como diversos clusters de regiões desenvolvidas e subdesenvolvidas em relação ao capital humano e áreas com melhor ou pior distribuição de renda. Ainda assim, a autocorrelação espacial diminui nas variáveis PIB per capita e IDHME no ano de 2010. A seguir, a próxima seção faz a análise bivariada do I de Moran, Diagrama de dispersão de Moran e os mapas dos clusters da estatística Lisa.

\subsection{ANÁLISE BIVARIADA}

A Tabela 5 traz os resultados do I de Moran para as variáveis Gini x IDHME defasado espacialmente, o valor da estatística está abaixo de seu valor esperado, evidenciando uma autocorrelação espacial negativa entre as variáveis, ou seja, municípios com alto índice de gini são cercados por outros de baixo índice de desenvolvimento (educação), e municípios com baixo índice de gini (menor desigualdade) são cercados por outros de alto índice de capital humano, indicando assim, que o capital humano defasado espacialmente pode influenciar as concentrações espaciais de desigualdade renda per capita nos municípios analisados. A Tabela 5 também mostra as estatísticas para as variáveis PIBPC x IDHME. Em contraste, essas apresentam autocorrelação espacial positiva nos dados, porém, em 2010 a variável passa a apresentar uma menor autocorrelação espacial global nos dados. 
Tabela 5 - I de Moran, Valor Esperado, Desvio Padrão e Pseudo-Valor P.

\begin{tabular}{lcccccccc}
\hline & \multicolumn{9}{c}{2000} & \multicolumn{5}{c}{2010} \\
\cline { 2 - 9 } & I de Moran & VE & DP & $\begin{array}{l}\text { Pseudo } \\
\text { valor-p }\end{array}$ & I de Moran & VE & DP & $\begin{array}{c}\text { Pseudo } \\
\text { valor-p }\end{array}$ \\
GINI x & $-0,3403$ & $-0,0025$ & 0,0234 & 0,001 & $-0,2699$ & $-0,0025$ & 0,0239 & 0,001 \\
IDHME & & & & & & & & \\
PIBPC x & 0,1048 & $-0,0025$ & 0,0234 & 0,001 & 0,0909 & $-0,0025$ & 0,0235 & 0,001 \\
IDHME & & & & & & & & \\
\hline
\end{tabular}

Fonte: Elaborado pelos autores a partir dos dados do IBGE e ATLAS.

Nota: Pseudo-significância baseada em 999 permutações aleatórias.

A Figura 7 mostra os diagramas de dispersão de Moran, que confirmam os resultados da estatística I de Moran, tendo o diagrama de GINI x IDHME uma reta negativamente inclinada e uma reta positivamente inclinada para as variáveis PIBPC x IDHME.

Por fim, analisa-se a associação espacial da estatística LISA, por meio de mapas. A Figura 8 evidencia os clusters para a análise Bivariada do Índice de GINI x IDHME. A Figura 9 por outro lado, evidencia os clusters para as variáveis PIBPC x IDHME.

Figura 7 - Diagramas de dispersão de Moran das análises bivariadas.

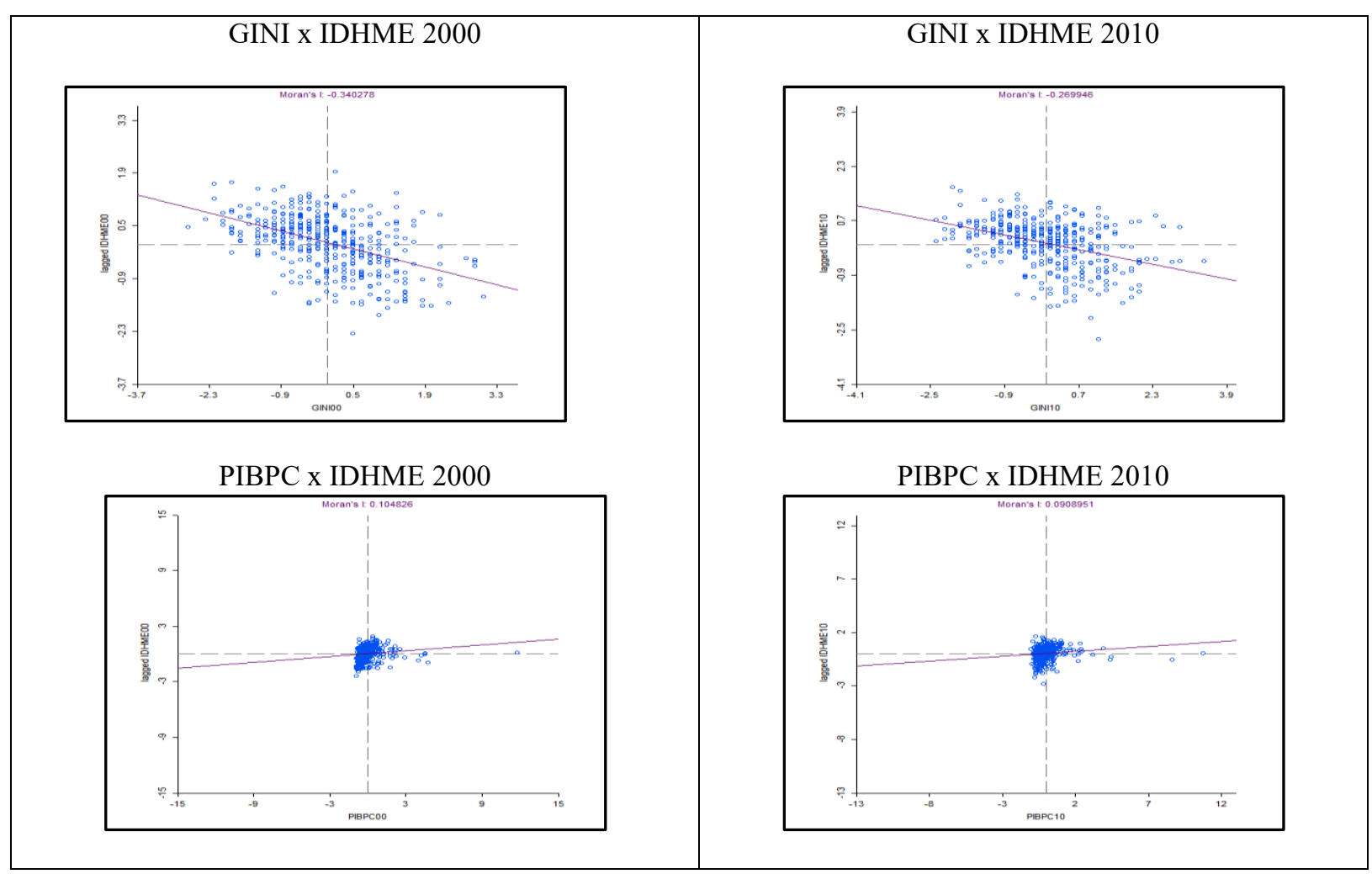

Fonte: Elaborado pelos autores a partir dos dados do IBGE e ATLAS. 
Figura 8 - Clusters para as variáveis GINI x IDHME

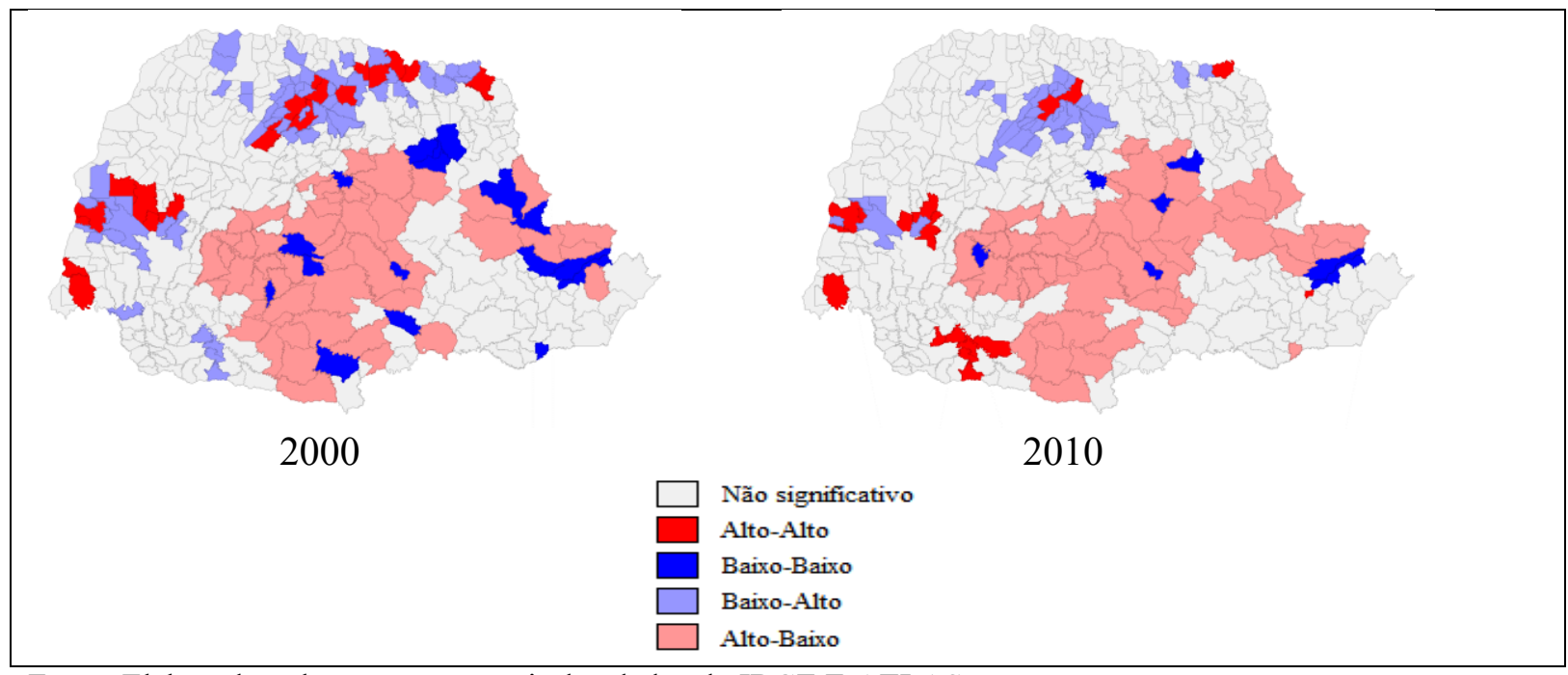

Fonte: Elaborado pelos autores a partir dos dados do IBGE E ATLAS.

Figura 9 - Clusters para as variáveis PIBPC x IDHME.

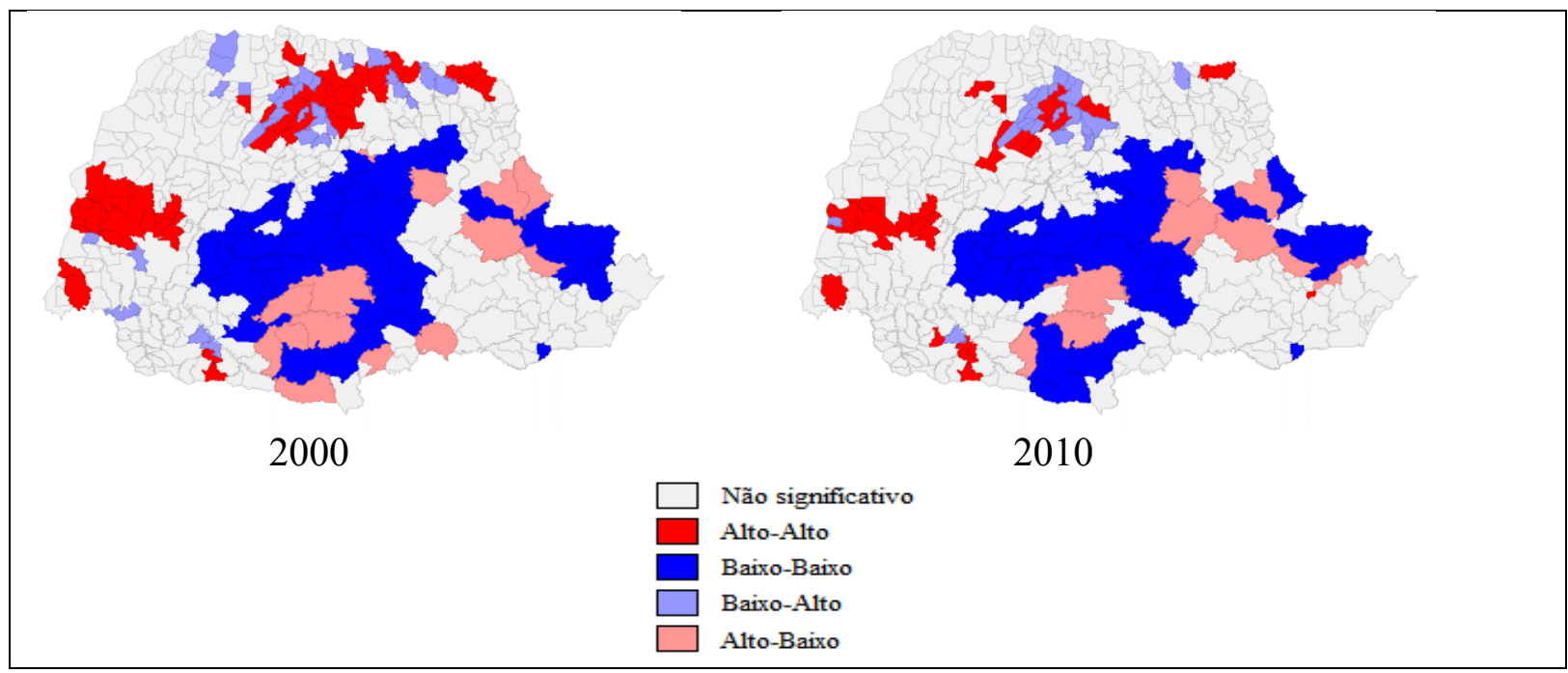

Fonte: Elaborado pelos autores a partir dos dados do IBGE E ATLAS.

Com base na análise de Clusters, evidencia-se autocorrelação espacial local entre as variáveis. Nota-se, que entre as variáveis GINI e IDHME os dados apresentam autocorrelação negativa, sendo os clusters AB (passa de 53 para 52) e BA (passa de 57 para 35) os mais significativos tanto em 2000, quanto em 2010, apesar da diminuição destes clusters no decorrer da década. Assim, em 2010, os 52 municípios incluídos nos clusters AB se localizam nas regiões destacas como de menor desenvolvimento nas outras análises, ou seja, principalmente no Centro Sul, Sudeste, Centro Ocidental, Centro Oriental, Norte Central, e Metropolitana de Curitiba. Tal como os outros indicadores, os clusters se concentram na região central do estado. Desta forma, o capital humano e as externalidades da educação parecem ser importantes fatores para a desigualdade regional. Em 2010 parece estar mais relacionado o baixo capital humano com regiões mais desiguais, em detrimento do alto capital 
humano com regiões de menor desigualdade de renda. Assim, o investimento em educação pode ser importante para diminuir disparidades de renda, podendo assim ajudar na convergência da renda per capita entre os municípios paranaenses.

Em relação à autocorrelação espacial das variáveis PIBPC e IDHME, os gráficos confirmam associação espacial local positiva entre as variáveis; os dados indicam que existe concentração acentuada de municípios com baixo PIB per capita cercados por municípios com baixo capital humano. As regiões autocorrelacionadas com clusters AA diminuem de 2000 para 2010 (de 48 municípios para 30). Os municípios que faziam parte de clusters BB passam de 58 para 50. Assim, mesmo com a diminuição das regiões AA e BB elas ainda são mais expressivas, demonstrando a autocorrelação entre PIB per capita e capital humano. Infere-se, portanto, que a educação aumenta a impacta a produção per capita municipal, sendo um dos possíveis fatores para tal o aumento da quantidade de tecnologia disponível, assim como ajuda na utilização das tecnologias já existentes (difusão) podendo ainda haver transbordamentos espaciais da mesma para os municípios vizinhos.

De acordo com Barros e Mendonça (1998), a educação tende a aumentar os salários via aumento de produtividade, aumentar a expectativa de vida à medida que os recursos familiares existentes são utilizados, reduzir o tamanho da família, aumentar a qualidade de vida e reduzir a pobreza no futuro. De fato, a correlação não indica causalidade, contudo teoricamente a educação gera o aumento do PIB per capita, assim como diminui o índice de Gini. Desta monta, o baixo nível de educação parece estar relacionado aos baixos índices de desenvolvimento municipais.

\section{CONSIDERAÇÕES FINAIS}

No presente trabalho foi possível demonstrar que houve melhorias no desenvolvimento do Paraná na década de 2000. Porém, quando analisadas as regiões do estado, evidencia-se uma grande concentração do valor adicionado setorial e do PIB sendo as regiões com maior concentração: Norte central Paranaense, Região Metropolitana de Curitiba e Oeste Paranaense.

Em relação à análise espacial, tanto univariada quanto bivariada, os dados demostraram estarem altamente correlacionados espacialmente, evidenciando grandes faixas de clusters. No período analisado, todas as estatísticas foram significativas estatisticamente (ao menos a 10\%), demonstrando assim, regiões de desigualdade/igualdade, mais/menos educadas e com maior/menor PIB per capita.

A análise bivariada, por sua vez, demonstra autocorrelação espacial negativa quando analisadas as variáveis GINI x IDHME defasado e autocorrelação espacial positiva quando analisadas as variáveis PIBPC x IDHME defasado. De fato, a educação pode ser um dos prováveis fatores de subdesenvolvimento e desigualdade dos municípios evidenciados nos clusters. O importante a se frisar é que existe uma grande autocorrelação espacial entre as variáveis e o capital humano (IDHME) e que nos dois casos se concentra principalmente nas regiões centrais do estado. Nesse caso, o investimento em educação poderá ser extremamente importante para melhorar o desenvolvimento e diminuir a desigualdade entre as regiões do

DRd - Desenvolvimento Regional em debate (ISSNe 2237-9029) 
estado no futuro, já que em 2010 os clusters mais expressivos para as variáveis GINI x IDHME foi $\mathrm{AB}$, ou seja, municípios com alta desigualdade de renda cercado por municípios com baixo capital humano, e para as variáveis PIBPC x IDHME o cluster mais expressivo foi $\mathrm{BB}$, ou seja, municípios com baixo PIB per capita (desenvolvimento) cercado por municípios com baixo capital humano.

Deste modo, o estudo aumenta o conhecimento sobre a importância do capital humano no desenvolvimento regional do Paraná, assim como melhora a compreensão sobre a evolução do desenvolvimento regional na década de 2000. É necessário frisar que apesar dos resultados evidenciados, o desenvolvimento não é dependente apenas do capital humano, deve-se salientar que, outros fatores são importantes para explicar a dinâmica regional, como políticas macroeconômicas exógenas a região, capacidade de internalizar o crescimento, cooperação entre estruturas produtivas, capacidade de exportação e de substituição, dentre outros.

Desta feita, para estudos futuros, abre-se uma opção de compreender, por exemplo, como o capital humano se relaciona com estes fatores, em que se sugere a utilização de uma Proxy qualitativa para o IDHME que possa captar tais efeitos de forma mais particularizada Sugere-se ainda analisar como o investimento em educação poderia melhorar o desenvolvimento nos municípios paranaenses, ou delinear qual o melhor tipo de investimento já que os investimentos podem ser em quantidade, qualidade, infraestrutura, capacitação de professores, salários, dentre outros.

\section{REFERENNCIAS}

ALMEIDA, E. Curso de econometria espacial aplicada. ESALQ-USP: Piracicaba, 2004.

; PEROBELLI, F. S.; FERREIRA, P.G. Existe convergência da produtividade agrícola espacial no Brasil? Revista de Economia e Sociologia Rural, v. 46, p. 31-52, 2008.

ANSELIN, L. Interactive techniques and exploratory spatial data analisys. In: LONGLEY, P.A. et al. (eds). Geographical information system: principles, techniques, management and applications. Wiley: New York. p 253-365, 1998.

. Local Indicators of Spatial Association - LISA. Geographical Analysis, v. 27, n.2, p. 93-115, 1995.

BARRETO, R. C. S; ALMEIDA, E. S.; LIMA, J. E. Convergência espacial do PIB per capita no estado do Ceará. Revista de Economia (Curitiba), v. 36, p. 25-40, 2010.

BARROS, R. P.; MENDONCA, R. S. Investimento em educação e desenvolvimento econômico. A economia brasileira em perspectiva. RJ: IPEA, 1998, p. 605-614.

BECKER, G. S. Human capital a theoretical and empirical analysis, with special reference to education. Third Edition, University of Chicago, NBER, New York, 1993. Disponível em:

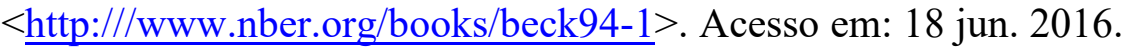


BOISIER, S.; HADDAD, P.R. Economia regional, teorias e métodos de análise. (Org). Fortaleza: BNB/ ETENE, 1989.

CANGUSSU, R.C.; SALVATO, M. A.; NAKABASHI, L. Uma análise do capital humano sobre o nível de renda dos estados brasileiros: MRW versus Mincer. Estudos Econômicos (USP. Impresso), v. 40, p. 153-183, 2010.

CLIFF, A. D; ORD, J. K. Spatial processes: Models \& applications. London: Pion, 1981.

COLMAN, D.; NIXSON, F. Desenvolvimento econômico: uma perspectiva moderna. Rio de Janeiro: Campus, 1981.

COSTA, A.M.B. et al. Comportamento espacial do índice de desenvolvimento humano no Rio Grande do Norte com o uso do programa TerraView (desenvolvido pelo INPE).. XIII SIMPÓSIO BRASILEIRO DE SENSORIAMENTO REMOTO, Florianópolis, Brasil, 21-26 abril 2007, Anais... Florianópolis: INPE, 2007. p. 5159-5166.

CRESSIE, N. A. C. Statistics for spatial data, revised edition. New York, John Wiley \& Sons Inc, 1993.

HIRSCHMAN, A. O. The strategy of economic development. New Haven: Yale University Press, 1958.

JACOBS, J. The Economy of Cities. New York: Random House, 1969.

KROTH, D. C.; DIAS, J. Os efeitos dos investimentos público e privado em capitais físico e humano sobre o produto per capita dos municípios da região Sul: uma análise em painéis de dados dinâmicos. Nova Economia (UFMG. Impresso), v. 22, p. 621-649, 2012.

LÁZARI, N. C. Educação e crescimento econômico: uma análise espacial para o Paraná entre 2000 e 2010. 2014. 60 f. Monografia (Graduação em Ciências Econômicas) Universidade Estadual de Londrina. Londrina, 2014.

LE GALLO, J.; ERTHUR, C. "Exploratory spatial data analysis of the distribution of regional per capita GDP in Europe, 1980-1995”. Papers in Regional Science, v. 82, n. 2, p. 175-201, 2003.

LIMA, V. M. A.; CALDARELLI, C. E.; CAMARA, M. R. G. Análise do desenvolvimento municipal paranaense: uma abordagem espacial na década de 2000. Economia e Desenvolvimento (Santa Maria), v. 26, p. 1-19, 2014.

LUCAS, R. E. Jr. On the mechanics of economic development. Journal of Monetary Economics, v. 22, n. 1, p. 3-42, 1988.

MYRDAL, G. Economic theory andunder-developed regions. Gerald Duckworth \& CO. LTD: London, 1957.

NAKABASHI, L.; FIGUEIREDO, L. Mensurando os impactos diretos e indiretos do capital humano sobre o crescimento. Revista de Economia Aplicada, v. 12, p. 151-171, 2008. 
NAKABASHI, L.; FIGUEIREDO, L. Capital humano: uma nova proxy para incluir aspectos qualitativos. Revista de Economia (Curitiba), v. 34, p. 07-24, 2008.

NORTH, D. C. Teoria da localização e crescimento econômico regional. In:

SCHWARTZMAN, J. Economia regional: textos escolhidos. Cedeplar, Belo Horizonte, 1977.

PEROBELLI, F. S.; FERREIRA, P.G.; FARIA, W.R. Análise de Convergência Espacial do PIB per-capita em Minas Gerais: 1975-2003. In: ENCONTRO REGIONAL DE

ECONOMIA; 11. 2006, Fortaleza. Nordeste: Estratégias de Desenvolvimento Regional.

Anais... Fortaleza: BNB, 2006.

PERROUX, F. A economia do século XX. Porto: Herder, 1967.

ROMER, P. Endogenous technological change. The Journal of Political Economy, v. 98, n. 5, p. 71-102, 1990.

SCHULTZ, T. W. Capital formation by education. The Journal of Political Economy, v. 68, n. 6, p. 571- 583, 1960. 1961.

Investment in human capital. The American Economic Review, v. 51, n. 1, p. 1-17,

. Reflections on investment in man. The Journal of Political Economy, v. 70, n. 5, p. $1-8,1962$

SILVA, W. P.; PARRE, J. L. A Violência no Estado do Paraná: Uma Análise Espacial das Taxas de Homicídios e de Fatores Socioeconômicos. In: ENCONTRO NACIONAL DA ASSOCIAÇÃO BRASILEIRA DE ESTUDOS REGIONAIS E URBANOS; 13. 2015, Curitiba. A Violência no Estado do Paraná: Uma Análise Espacial das Taxas de Homicídios e de Fatores Socioeconômicos, 2015.

SOLOW, R. M. A contribution to the theory of economic growth. The Quarterly Journal of Economics, v. 70, n. 1, p. 65-94, 1956.

SOUZA, N. J.; OLIVEIRA, J. C. Relações entre geração de conhecimento e crescimento econômico. Análise, Porto Alegre, v. 17, n. 2, p. 211-223, jul./dez. 2006.

Artigo recebido em: 26/01/2016

Artigo aprovado em: 10/08/2016 